\title{
Service-Learning in an Undergraduate Abnormal Psychology Course: What Do Students Learn?
}

\author{
Christina Michaelson ${ }^{1}$ \\ ${ }^{1}$ Department of Psychology, Le Moyne College, Syracuse, New York, USA \\ Correspondence: Christina Michaelson, Department of Psychology, Le Moyne College, Syracuse 13214, NY, USA. \\ Tel: 315-445-4335.
}

Received: May 29, 2018

Accepted: June 16, 2018

Online Published: June 23, 2018

doi:10.5430/irhe.v3n2p125

URL: https://doi.org/10.5430/irhe.v3n2p125

This manuscript is based on data previously presented at the $8^{\text {th }}$ Biennial Convention of the Society for the Psychological Study of Social Issues, New Orleans, LA, June 2010.

\begin{abstract}
In my Abnormal Psychology course students reported that their service-learning work at mental health related organizations in the community helped them connect course content to life experiences, increase their understanding of the impact of mental illness on people's lives, and examine their attitudes about people with psychological disorders. They also developed increased empathy, greater understandings of cultural and racial differences, and more awareness of their personal strengths. They felt useful to others, that their service made a difference, and that they were more likely to volunteer in the future. These results are consistent with previous research that service-learners increase their understanding of course content and experience personal growth. The present study provides a more focused perspective on how Abnormal Psychology students are affected specifically by their experiential understanding of psychological disorders and reflection on their attitudes about mental illness.
\end{abstract}

Keywords: service-learning, abnormal psychology, psychological disorders, empathy

\section{Introduction}

Including a service-learning component in academic courses promotes benefits for students on an array of measures, depending on the course content and the service-learning opportunities (Aldridge, Callahan, Chen, \& Wade, 2015; Blieszner \& Artale, 2001; Chrisman-Khawam, Abdullah, \& Dhoopar, 2017; Hollis, 2004; Peters, 2011; Weiler, Haddock, Zimmerman, Krafchick, Henry, \& Rudisill, 2013). Abnormal psychology courses, in particular, can provide opportunities for students to increase their knowledge and understanding of psychological disorders through service-learning work that connects them with individuals with mental illnesses and organizations providing mental health care services. Bringle, Reeb, Brown, and Ruiz (2016) emphasized that including a service-learning component in an Abnormal Psychology course can provide students with the opportunity to "apply the theory and research from these courses to make community contributions and reflect on experiences in ways that augment their academic learning, civic learning, and personal growth" (p. 106). Throughout several years of teaching an Abnormal Psychology course with service learning experiences, students often reported in their reflection papers and in class discussions that they felt profoundly affected by their service-learning commitments, and I consistently wondered how they specifically were changed by their work in the community. The purpose of the learning outcomes assessment described in this paper was to explore the value to students of including service-learning as a pedagogical technique.

\subsection{Course Goals}

The primary learning goal in my Abnormal Psychology course was to help students understand a broad range of diagnostic categories, etiologies, and treatments of psychological disorders. My secondary goal was to encourage students to move beyond academic knowledge about the disorders to deeper understandings of the experiences of individuals living with mental illness. To address these goals I incorporated several pedagogies into the course including lecturing, discussing case studies, inviting guest speakers into class who were challenged by living with a psychological disorder, and offering service-learning opportunities at mental health related organizations throughout 
the community. The service-learning component of this course was designed to allow students to interact directly with and provide support to people in the community with mental illness and concurrently to reflect on how they were changed by their service-learning experiences.

The service-learning component of this course was guided by the model outlined by Bringle and Hatcher (1995). They described service learning as

a course-based, credit-bearing educational experience in which students (a) participate in an organized service activity that meets identified community needs and (b) reflect on the service activity in such a way as to gain further understanding of course content, a broader appreciation of the discipline, and an enhanced sense of civic responsibility. This is in contrast to co-curricular and extracurricular service, from which learning may occur, but for which there is no formal evaluation and documentation of academic learning. (p. 112)

Consistent with this description, the learning objectives for students' service-learning experiences in this course included the following:

- to learn more about psychological disorders and treatments through providing service to people and mental health care agencies in the community;

- to observe and experience the impact of mental illness on people's lives, their families, mental health providers, and the mental health care system;

- to fulfill important needs in the community, feel useful to others, and address issues of social justice;

- through written reflection papers, to explore and clarify your values, attitudes, and career goals; and

- to challenge yourself in new situations and recognize your strengths.

\subsection{Service-Learning Requirements}

Students' service-learning responsibilities for the course required working for two hours a week for ten weeks during the semester. Service-learning sites included work at a variety of community agencies such as after-school tutoring programs for at-risk children and teens, safe houses for people affected by domestic violence, support groups for people with depression, inpatient psychiatric units, and residential facilities and treatment programs for people challenged by substance abuse and homelessness.

Students were required to complete a Reflection Journal every two weeks during their service-learning experiences and were asked to address the following topics in each journal:

- What are your specific goals for what you want to learn in your service-learning work, and what is your progress toward your goals? What are your successes and challenges in your work?

- What are your observations about the structure and operation of the agency at which you are working? What are their successes and challenges?

- What are the connections you are making between your service-learning work and course content? Each paper must include at least one new connection.

- Discuss an aspect of your service-learning that has stimulated your thinking. How has your work challenged your thinking, your beliefs, and your values?

The final component of the service-learning project was for students to present to the class a summary of their experiences and learning. The goal of these presentations was for class members to develop a broader perspective of mental health care needs and services in the community based on their own and other students' experiences at the various service-learning sites. In addition to the service-learning project, additional requirements of this course included four exams and one case study presentation.

\section{Method}

\subsection{Participants}

The participants were 49 students enrolled in two sections of my Abnormal Psychology course at a small, private, liberal arts college in upstate New York. This class was an elective undergraduate course. Participants included $73.5 \%$ females and $26.5 \%$ males, and the mean age was 21.84 years old, with a range from 19-43 years old. More than half of participants were juniors $(53.1 \%), 30.6 \%$ were seniors, $12.2 \%$ were sophomores and $4.1 \%$ were first year students. 


\subsection{Materials}

To assess learning outcomes for students participating in service-learning, I utilized three questionnaires. I designed the first questionnaire, Service-Learning Outcomes, to assess specific course content regarding psychological disorders and the delivery of mental health care services in the community. The second instrument was the Service Learning Benefit Scale constructed by Toncar, Reid, Burns, Anderson, and Nguyen (2006), and the third assessment questionnaire was a Student Survey developed by Gelmon, Holland, Driscoll, Spring, and Kerrigan (2001). The evaluation data were collected in class during the last week of the semester, after students completed their service-learning projects and service-learning class presentations.

\section{Results}

\subsection{Service-Learning Outcomes Questionnaire}

On a rating scale ranging from 1 (not at all helpful) to 5 (very helpful), students' mean scores on the Service-Learning Outcomes questionnaire that I constructed indicated that through service-learning they most strongly felt they were of service to others $(M=4.53, S D=0.65)$ and that service-learning helped them recognize more about their own strengths and their ability to challenge themselves in new situations $(M=4.27, S D=1.04)$. Related to course content, they found service-learning helpful in understanding the impact of mental illness on the individual $(M=4.18, S D=1.11)$ and in understanding more about the mental health care needs in the community $(M$ $=4.12, S D=1.01)$. Students also found service-learning helpful in examining their views about people with mental illness $(M=4.06, S D=0.99)$ and in understanding more about psychological disorders $(M=3.98, S D=0.92)$. To a lesser degree, students reported that service-learning was somewhat helpful to them in understanding the delivery of mental health care services at their community site $(M=3.71, S D=1.03)$ and in exploring their career goals $(M=$ $3.61, S D=1.11)$.

\subsection{Service-Learning Benefit Scale}

On the Service Learning Benefit Scale (Toncar, Reid, Burns, Anderson, \& Nguyen, 2006), students' mean scores (N $=47$ ) on a rating scale ranging from 1 (not at all) to 7 (very much so) indicated that they endorsed most strongly that service-learning provided them the opportunity to develop empathy and sensitivity to the plight of others $(M=6.45$, $S D=0.72$ ). They also reported that through their service-learning work, they felt they made a difference in the community $(M=6.26, S D=0.90)$, increased their understanding of cultural and racial differences $(M=6.19, S D=$ $0.92)$, and were able to apply their knowledge to the "real world" $(M=6.17, S D=1.15)$. Additionally, students experienced personal growth $(M=6.13, S D=1.06)$, acquired skills in learning from experience $(M=6.13, S D=$ $1.23)$ and in communicating $(M=6.00, S D=0.93)$, and felt involved in the community $(M=6.00, S D=1.08)$.

Slightly less strongly, students endorsed that they experienced the following benefits from service-learning: social responsibility and citizenship skills $(M=5.94, S D=0.99)$, gaining the trust of others $(M=5.94, S D=1.15)$, ability to work with others $(M=5.93, S D=1.03)$, connecting theory with practice $(M=5.87, S D=1.23)$, social self-confidence $(M=5.81, S D=1.01)$, development of caring relationships $(M=5.79, S D=1.30)$, ability to assume personal responsibility $(M=5.77, S D=1.07)$, and problem analysis and critical thinking skills $(M=5.64, S D=1.15)$. Additional skill acquisition for students included workplace skills $(M=5.64, S D=1.31)$, conflict resolution skills $(M$ $=5.55, S D=1.10)$, leadership skills $(M=5.51, S D=1.28)$, and organization skills. $(M=5.00, S D=1.56)$.

\subsection{Student Survey}

On the Student Survey developed by Gelmon, Holland, Driscoll, Spring, and Kerrigan (2001), participants' mean scores on a rating scale ranging from 1 (strongly disagree) to 5 (strongly agree) revealed the strongest agreement that they had the opportunity to discuss their service-learning in class and connect their work to course content $(M=$ $4.63, S D=0.70$ ). They also strongly agreed that they felt a personal responsibility to meet the needs of their community partner site $(M=4.55, S D=0.61)$ and that service-learning helped them to apply course content to everyday life $(M=4.53, S D=0.54)$. They also agreed that they worked directly with their community partners $(M=$ $4.50, S D=0.62)$, that the syllabus integrated service-learning with course objectives $(M=4.47, S D=0.77)$, and that service-learning enhanced their learning in the course $(M=4.43, S D=0.68)$.

Regarding personal growth, students reported on the Student Survey that service-learning helped them become aware of their strengths and weaknesses $(M=4.41, S D=0.79)$ and enhanced their communication skills in "real world" settings $(M=4.33, S D=0.72)$. There was agreement that more classes on campus should include service-learning experiences $(M=4.33, S D=0.85)$, and students disagreed that they would not volunteer in the community in the future $(M=1.63, S D=0.93)$. Students also reported that they felt that their service-learning work benefited the 
community $(M=4.31, S D=0.74)$, helped them become more aware of their own biases and prejudices $(M=4.18$, $S D=0.70)$, and helped them to better understand the lectures and readings in the course $(M=4.18, S D=0.75)$.

\section{Discussion}

\subsection{What Did Students Learn in the Present Study?}

The results of this learning outcomes assessment demonstrate that students benefited in many ways from participating in service-learning in this Abnormal Psychology course. Related to course content, service-learning helped students connect academic information to everyday life. Specifically, students increased their understanding of how people are affected by mental illness and increased their recognition of mental health care needs in the community. They also developed a broader understanding of psychological disorders, enhanced their understanding of course content, and endorsed that their work challenged them to examine their views and prejudices about people with mental illness. Students reported that service-learning was well integrated into course objectives and class discussions and that more classes on campus should include service-learning. Due to their work, students became more likely to volunteer in the community in the future.

In terms of personal growth, students indicated that their service-learning work helped them develop empathy, sensitivity to others' life challenges, and an increased understanding of cultural and racial differences. They also felt useful to others and that their service in the community made a difference. They became more aware of their personal strengths and their capacity to meet challenges, and they developed a myriad of abilities including communication skills, learning from experience, increased social responsibility, and building caring relationships.

\subsection{What Did Students Learn in Other Service-Learning Courses in Psychology?}

These results are consistent with findings from several previous studies. Reeb, Saamon, and Isackson (1999) also found that students benefited from participating in service-learning in an Abnormal Psychology course. In their study, service-learners achieved higher scores on exams in the course and also evaluated aspects of the course more highly, including that they learned a lot, became more interested in course topics, and learned to apply class content to life experiences compared to students who did not participate in service-learning. Service-learners also reported greater commitment to social responsibility in areas such as desiring to be of service to others and engaging in social justice work compared to other students. Also in an Abnormal Psychology course that included spending 10 hours with individuals with mental illnesses, students reported significant decreases in stigma about mental illness, compared to students in an Abnormal Psychology course that did not include service-learning requirements (Barney, Corser, Strosser, Hatch, and LaFrance, 2017).

In a Developmental Psychology course, students participating in service-learning achieved higher performance on most exams compared to those who were not engaged in service-learning. They also reported a significantly higher level of empathy at the end of their community work compared to the beginning of the course, while students engaged in projects other than service-learning actually experienced a decrease in empathy over the course of the academic term (Lundy, 2007). In a lifespan developmental course at the graduate level, students engaged in a home visiting program to provide support and information to vulnerable families. Following their service-learning work, students reported an increased sense of responsibility to the families with whom they were working, and some students increased their critical thinking abilities regarding analyzing social challenges (Campbell \& Oswald, 2018).

When service-learning was included in a General Psychology course, the majority of students reported that their experiences increased their feelings of social responsibility and their understanding of course material (Kretchman, 2001). Students in a psychology course studying disabilities who engaged in service-learning focused on interacting with and engaging in activities with people with disabilities at a nonprofit organization reported at the end of the semester significantly changed attitudes about people with disabilities, including increases in comfort with and information about people with disabilities. The authors suggest that these changed attitudes may be beneficial in the future to students in their professional work with people with disabilities (Carlson \& Witschey, 2018).

In a meta-analysis of the effects of service-learning, Conway, Amel, and Gerwien (2009) found positive changes in a variety of outcomes, including academic motivation to learn and knowledge about and attitudes toward those receiving services. Based on their results, they recommended that psychologists include service-learning in more of their courses. All of these research results, along with the present study, strongly support multiple benefits for students participating in service-learning work and I hope also may serve as a catalyst for faculty to consider including service-learning opportunities in their courses. 


\subsection{Limitations}

The present study utilized only descriptive statistics, and all participants were engaged in service-learning experiences. Future research should compare Abnormal Psychology students who are and are not involved in service-learning and also should test for changes in students' responses by comparing data collected before and after their participation in service-learning. The number of participants in the present study was relatively small, and therefore, future studies should include a larger sample size and also should compare samples of participants from differing colleges and universities, particularly those of varying sizes and locations in urban, suburban, and rural areas.

\section{Conclusion}

The results of the present study support many pedagogical advantages of service-learning as students moved beyond an academic understanding of psychological disorders to actively experiencing the effects of mental illness on individuals and on the community, also while reflecting on their own personal transformations. Consistent with previous outcome results, the students in the present study experienced personal growth through developing empathy, skill acquisition, and an increased sense of responsibility to be of service to others. As previous researchers also have found, students in this study expanded their understanding of course content through their service-learning experiences. However, the present study provides an extended and more focused perspective on how students were affected in an Abnormal Psychology class through their service work. Specifically related to the content of the course, students learned through service-learning how mental illness affects individuals and communities, and they were prompted through their reflection papers to consider their views and prejudices about people with mental illness. Thus, in addition to the general benefits of service-learning, these community opportunities should be offered to Abnormal Psychology students so that they may increase their experiential understanding of psychological disorders and reflect on their attitudes about mental illness. In turn, this may have the added benefit of decreasing cultural stigma towards those challenged by psychological illnesses and serve as an encouragement for students to develop careers of caring and advocating for people with mental illnesses in more informed and compassionate ways.

\section{References}

Aldridge, R., Callahan, R. A., Chen, Y., \& Wade, S. R. (2015). Income tax preparation assistance service learning program: A multidimensional assessment. Journal of Education for Business, 90, 287-295. https://doi.org/10.1080/08832323.2015.1034065

Barney, S. T., Corser, G. C., Strosser, G. L., Hatch, D. L., \& LaFrance, K. (2017). Service-learning in Abnormal Psychology: Softening the implicit stigma against the mentally ill. Scholarship of Teaching and Learning in Psychology, 3, 151-162. https://doi.org/10.1037/st10000083

Blieszner, R., \& Artale, L. M. (2001). Benefits of intergenerational service-learning to human services majors. Educational Gerontology, 27, 71-87. https://doi.org/10.1080/036012701750069058

Bringle, R. G., \& Hatcher, J. A. (1995). A service-learning curriculum for faculty. Michigan Journal of Community Service-Learning, 2, 112-122. http://hdl.handle.net/2027/spo.3239521.0002.111

Bringle, R. G., Reeb, R. N., Brown, M. A., \& Ruiz, A. I. (2016). Integrating service learning into the curriculum: Abnormal, Health, and Community Psychology. Service learning in psychology: Enhancing undergraduate education for the public good. Washington, DC: American Psychological Association. https://doi.org/10.1037/14803-006

Campbell, C. G., \& Oswald, B. R. (2018). Promoting critical thinking through service learning: A home-visiting case study. Teaching of Psychology, 45, 193-199. https://doi.org/10.1177/0098628318762933

Carlson, W., \& Witschey, H. (2018). Undergraduate students' attitudes toward individuals with disabilities: Integrating psychology disability curriculum and service-learning. Teaching of Psychology, 45, 189-192. https://doi.org/10.1177/0098628318762929

Chrisman-Khawam, L., Abdullah, N., \& Dhoopar, A. (2017). Teaching health-care trainees empathy and homelessness IQ through service learning, reflective practice, and altruistic attribution. The International Journal of Psychiatry in Medicine, 52(3), 245-254. https://doi.org/10.1177/0091217417730288

Conway, J. M., Amel, E. L., \& Gerwien, D. P. (2009). Teaching and learning in the social context: A meta-analysis of service learning's effects on academic, personal, social, and citizenship outcomes. Teaching of Psychology, 36, 233-245. https://doi.org/10.1080/00986280903172969 
Gelmon, S. B., Holland, B. A., Driscoll, A., Spring, A., \& Kerrigan, S. (2001). Assessing service-learning and civic engagement: Principles and techniques. Rhode Island: Campus Compact.

Hollis, S. A. (2004). Blaming me, blaming you: Assessing service learning and participants' tendency to blame the victim. Sociological Spectrum, 24, 575-600. https://doi.org/10.1080/02732170490448829

Kretchmar, M. D. (2001). Service Learning in a general psychology class: Description, preliminary evaluation, and recommendations. Teaching of Psychology, 28, 5-10. https://doi.org/10.1207/S15328023TOP2801_02

Lundy, B. L. (2007). Service learning in life-span developmental psychology: Higher exam scores and increased empathy. Teaching of Psychology, 34, 23-27. https://doi.org/10.1080/00986280709336644

Peters, K. A. (2011). Including service learning in the undergraduate communication sciences and disorders curriculum: Benefits, challenges, and strategies for success. American Journal of Audiology, 20, 181-196. https://doi.org/10.1044/1059-0889(2011/10-0031)

Reeb, R. N, Sammon, J. A., \& Isackson, N. L. (1999). Clinical application of the service-learning model in psychology: Evidence of educational and clinical benefits. Journal of Prevention \& Intervention in the Community, 18, 65-82. https://doi.org/10.1300/J005v18n01_06

Toncar, M. F., Reid, J. S., Burns, D. J., Anderson, C. E., \& Nguyen, H. P. (2006). Uniform assessment of the benefits of service learning: The development, evaluation, and implementation of the SELEB Scale. Journal of Marketing Theory and Practice, 14, 223-238. https://doi.org/10.2753/MTP1069-6679140304

Weiler, L., Haddock, S., Zimmerman, T. S., Krafchick, J., Henry, K., \& Rudisill, S. (2013). Benefits derived by college students from mentoring at-risk youth in a service-learning course. American Journal of Community Psychology, 52, 236-248. https://doi.org/10.1007/s10464-013-9589-z 